on the other hand, be given ton little heed; for it must be kept in mind that the co-existence of hysteria with tuberculosis of the lungs occurs frequently enough and that we have to deal with a very disturbing element in a disease sufficiently serious without it. When it is possible to demonstrate that blood-spitting is produced by sucking.or pricking the gums, wounding the nasal or buccal mucous membrane, the approved medicinal and psychic resources may be confidently turned to account. When this evidence is lacking, however, a hysterical individual suffering from hemoptysis should be treated for the blood-spitting, with little regard for the nervous condition which may be an accidental, not a causative, complication.

Finally, it is of some importance to be alive to the occasional occurrence of malingering. There is always a certain number of people who manage adroitly to deceive one into the belief that they are spitting blood, their object being to obtain sick benefit, to escape work or to enter a comfortable institution. It is often difficult to trap these people and to expose the spurious nature of the complaint, but one who is on his guard and who has much to do with genuine cases of pulmonary hemorrhage will usually be able to classify them in their proper category.

I have not gone into the matter of conditions other than pulmonary tuberculosis which may have hemorrhage as a prominent symptom. In most instances, a hemorrhage from the lungs means phthisis of that organ, but we can not forget the by no means rare cases of blood-spitting in bronchiectasis and in mitral stenosis.

\section{A SHAWL PIN IN THE MALE URETHRA}

\section{B. CLARK HYDE, M.D.}

KANSAS CITY, Mo.

Patient.-E. P., white, aged 13, a schoolboy, was admitted to Kansas City Post-Graduate Hospital, Nov. 23, 1908.

Previous $\boldsymbol{H}$ istory.-The patient stated that on the night of Nov. 19, 1908, in attempting to remove an accumulation of dirt or foreign matter from the glans penis, he had passed a shawlpin head first into the urethra, and it had slipped away from his grasp and become fastened in the urethra. He denied sexual perversion.

Present Condition.-The boy is well nourished and well-developed. Intellectually, he seems below normal and has a peeuliar defect in speech, something between a lisp and a stammer. He complains of nothing referable to bladder or otherwise, and passes urine without difficulty. He was brought to the hospital by his father because the boy had told him of losing the pin in his urethra, not because of any particular discomfort caused by the foreign body.

Examination.-The prepuce could be easily retracted from glans; the penis was well developed. At the penoscrotal angle, deep in the tissues, could be felt a round mobile mass about the size of a pea. Nothing like the shaft of a pin could be outlined or palpated. There was no particular pain on palpation of the foreign body, which was considered to be in all probability the head of the pin.

Roentgen Examination: An $x$-ray photograph was taken by Dr. E. H. Skinner, the hospital roentgenologist. It showed the pin lodged in the membranous urethra, with an apparent shortening of the pin to about one-half its size, its actual length being six centimeters. The picture seemed to confirm the opinion that the small mass felt at the floor of the urethra was the pin's head.

Operation.-Nov. 24, 1908, after the usual surgical preparation, an incision was matle at the pengserotal angle along the urethra, over the small round mass. It had been anticipater that when the incision reached the urethra, the head of the pin could be grasped and withdrawn; however, on approaching the urethra it was discovered that it was the point of the pin which had been nearest the surface, and that the rounded feeling imparted to the touch had been caused by the stretching of the tissues over, and, as it were, "padding" the point. The head of the pin rested in the bladder, into which viscus the entire pin had been denied ingress only because of the length and lack of flexibility of its shaft. The point of the pin was grasped by forceps and drawn through the, as yet unopened, floor of the urethra into the wound. Its entire removal was prevented by the pin head coming in contact with the urethral floor. Instead of enlarging the opening in the urethra to a sufficient size to permit the delivery of the head, the following procedure was adopted: the head of trie pin was turned toward the external meatus and passed along the urethra until it could be grasped by a forceps introduced through the meatus, by which route the corpus delicti was easily extracted. This left only a very small puncture in the floor of the urethra, merely large enough to admit the diameter of the shaft. The wound was closed by three deeply placed silkworm-gut sutures.

Subsequent History.-The patient suffered from nausea for four hours. He was catheterized seven hours after the operation, four ounces of urine being obtained; afterward he voided urine naturally. He passed a good night and was put on gen. eral diet the next day. There was never any leakage of urine through the operative wound, which healed perfectly. The stitches were removed on the seventh day following operation, on which day the boy left the hospital. He has remained in good health since.

\section{CYSTS WITHIN THE SPINAL CANAL \\ M. A. BLISS, M.D. \\ ST. LOUIS}

Krauss ${ }^{1}$ reviews eleven cases of cyst of the spinal canal. Of these only one, that of Spiller ${ }^{2}$ appears to be identical with the one herewith reported. Spiller ${ }^{3}$ says: "A collection of clear fluid in a cyst of the spinal pia arachnoid is a condition little known in America, as only one case occurring in this country is on record (Spiller, Musser and-Martin), and only a few are found in the German literature. So far the French and English journals contain no examples."

History.-Miss M., a patient of Dr. Willis Hall of this city, aged about 50, was well and always very active up to August, 1905. In jumping from a rapidly moving buggy she fell heavily on the left buttock. The left ankle was broken. The hip continued to hurt after the ankle healed, and since the accident she has suffered from a "shifting neuralgia." She felt after the accident that "her spine was all jolted up." The gait was at times disturbed by the pain in the left hip. In 1906 (date can not be fixed) the patient suffered severely from pain across the chest at the upper level of the breasts. This increased through 1907. In March, 1907, she had a hard fall in a railway coach, which made her sore all over but produced no local pain. In April, 1908, the patient was in St. Luke's Hospital three weeks on account of pain across the front of the chest. In El Paso, Texas, she had "grip" (?) in August, 1908; she had no cough, no cold in her head, but ached all over, most intolerably in her hips and back. About the same time severe cramping occurred in her legs. When out riding she would frequently have to stand up in the carriage on account of the cramping. By the last of August she became extremely awkward in her gait.

Dr. Fry, who saw the patient September 5, noticed that incoordination of gait and station was the most conspicuous symptom of the case at that time. He noted also loss of pain and temperature sense with fair preservation of tactile sense in her legs.

About October 1 she became entirely paraplegic. The muscular contractures and startings were more severe. If the legs

1. In Brain, 1, 1907, Part CXX, 533.

2. Univ. Penn. Bull., March and April, 1903

3. Am. Jour. Med. Sc., January, 1909, p. 95. 